\title{
PERBANDINGAN CDI STANDAR DAN CDI VARIASI TERHADAP PERFORMA MOTOR 4 TAK 100 CC
}

\section{COMPARISON STANDARD CDI AND VARIATIONS TO MOTORCYCLE PERFORMANCE 4 TAK $100 \mathrm{CC}$}

\author{
Ikhfan Tri Wahyulianto Putra ${ }^{*}$, Nely Ana Mufarida, S.T., M.T. ${ }^{2}$, Asmar Finali, S.T., M.T. $^{3}$ \\ ${ }^{1}$ Mahasiswa, ${ }^{2}$ Dosen Pembimbing 1, ${ }^{3}$ Dosen Pembimbing 2, Program Studi Teknik Mesin, Fakultas Teknik, \\ Universitas Muhammadiyah Jember \\ *Email : ikhfantri@gmail.com
}

\begin{abstract}
ABSTRAK
Motor bakar torak bensin merupakan mesin pembangkit tenaga yang mengubah bahan bakar bensin menjadi tenaga panas dan akhirnya menjadi tenaga mekanik. Pada saat awal sepeda motor mulai diproduksi sistem pengapian pada motor bensin menggunakan sistem pengapian konvensional (platina). Sistem pengapian sepeda motor sekarang kebanyakan menggunakan system pengapian CDI (Capacitor Discharge Ignation) yang memiliki karakteristik lebih baik di bandingkan dengan system pengapian konvensional.Sistem pengapian merupakan sistem yang sangat penting pada speda motor. Metode eksperimental adalah metode yang digunakan untuk menguji pengaruh dari suatu perlakuan atau desain baru dengan cara membandingkan desain tersebut dengan desain tanpa perlakuan sebagai kontrol atau pembanding.melakukan pengambilan data torsi dan daya dan pengaruh bahan bakar terhadap performa motor 4 tak $100 \mathrm{cc}$ tersebut dilakukan dengan proses dial Test.

Kata Kunci: Performa CDI, Daya, Torsi, Konsumsi Bahan Bakar.
\end{abstract}

\section{ABSTRACT}

Motor fuel torak gasoline is a power plant that converts gasoline into heat energy and eventually become mechanical power. At the beginning of the motorcycle began to be produced ignition system on gasoline motor using conventional ignition system (platinum). Motorcycle ignition system is now mostly using the system CDI (Capacitor Discharge Ignation) ignition which has better characteristics compared with conventional ignition system. The ignition system is a very important system on the motor speda. Experimental method is a method used to test the effect of a new treatment or design by comparing the design with design without treatment as a control or comparison. performs data and torque data and the effect of fuel on motor performance of $4100 \mathrm{cc}$ is done by the process of Test dial.

keywords: CDI performance, power, torque, fuel consumption.

\section{PENDAHULUAN}

Kemajuan ilmu pengetahuan dan teknologi saat ini terus berkembang pesat seiring dengan permasalahan yang terus bermunculan dan semakin komplek pada berbagai bidang kehidupan, termasuk dalam bidang transportasi. Sistem pengapian khususnya pada motor bensin 4 langkah telah mengalami banyak penyempurnaan. Pada saat awal sepeda motor mulai diproduksi sistem pengapian pada motor bensin menggunakan sistem pengapian konvensional (platina). Sistem pengapian konvensional merupakan sistem pengapian yang menggunakan platina (contact breaker) untuk memutus dan menghubungkan tegangan baterai ke kumparan primer.

Sistem pengapian konvensional (Platina) kini mulai di tinggalkan. Sistem pengapian sepeda motor sekarang kebanyakan menggunakan system pengapian CDI (Capacitor Discharge Ignation) yang memiliki karakteristik lebih baik di bandingkan dengan system pengapian konvensional. System pengapian CDI (Capacitor Discharge Ignition) atau system pengapian pelepasan kapasitor adalah salah satu sistem pengapian yang menggunakan relai/saklar dengan sistem elektronik untuk mengganti alat pengatur arus secara mekanik (Platina) dapat 
meningkatkan tegangan yang terjadi pada kumparan sekunder. Sehingga pada penggunaan sistem pengapian CDI akan berpengaruh terhadap kesempurnaan pembakaran dan daya yang di hasilkan oleh mesin.

Untuk mengatasi kelemahan dari CDI limiter (standar) ini dan akan untuk memperoleh performa mesin yang lebih optimal,pada saat ini banyak pabrikan CDI yang menawarkan CDI unlimiter (BRT powermax hyberband) sebagai pengganti cdi limiter.CDI unlimiter adalah CDI yang kerjanya tanpa ada batasan pengapian dan mampu melayani kerja mesin pada RPM tinggi tergantung dari seberapa kuat mesin sepeda motor tersebut berputar.Sehingga dengan tidak adanya batasan dalam pengapiannya diharapkan performa mesin akan mencapai performa yang maksimal.

Rumusan masalah yang akan dikaji dalam penelitian ini adalah sebagai Berikut:

1. Bagaimana perbedaan daya dan torsi pada sepeda motor yang mempergunakan CDI standart dan CDI variasi

2. Bagaimana perbedaan konsumsi bahan bakar pada sepeda motor yang mempergunakan CDI standart dan CDI variasi.

Agar permasalahan dalam penelitian ini menjadi jelas dan tidak menyimpang dari tujuan yang telah ditetapkan maka perlu membatasi beberapa masalah pada variabel yang akan di teliti, meliputi daya (hp), torsi $(\mathrm{Nm})$ dan konsumsi bahan bakar (L/h).

Tujuan dari penelitian ini adalah Untuk mengetahui perbedaan konsumsi bahan bakar premium pada sepeda motor 100 cc yang mempergunakan CDI limiter dan CDI unlimiter.

Manfaat yang ingin dicapai dalam melakukan penelitian adalah Sebagai masukan bagi pemilik dan pengguna kendaraan tentang pengaruh penggunaan CDI unlimiter terhadap daya, torsi dan konsumsi bahan bakar pada sepeda motor untuk menambah wawasan bagi mahasiswa terutama mahasiswa otomotif tentang pengaruh penggunaan CDI unlimiter sebagai salah satu langkah alternatif dalam memodifikasi kendaraan. Untuk menambah wawasan bagi mahasiswa terutama mahasiswa teknik mesin tentang pengaruh CDI variasi sebagai salah satu langkah alternatif dalam memodifikasi kendaraan. Sebagai masukan bagi industri dan pengguna kendaraan tentang pengaruh penggunaan CDI variasi terhadap daya, torsi dan konsumsi bahan bakar pada sepeda motor.

\section{TINJAUAN PUSTAKA}

Motor Bakar

Motor bakar adalah salah satu bagian dari mesin kalor yang berfungsi untuk mengkonversi energi termal hasil pembakaran bahan bakar menjadi energi mekanis. Terjadinya energi panas karena adanya proses pembakaran, bahan bakar, udara, dan sistem pengapian. Dengan adanya suatu konstruksi mesin, memungkinkan terjadinya siklus kerja mesin untuk usaha dan tenaga dorong dari hasil ledakan pembakaran yang diubah oleh konstruksi mesin menjadi energi mekanik atau tenaga penggerak.

\section{Sistem Pengapian}

Awal atau permulaan pembakaran sangat diperlukan karena, pada motor bensin pembakaran tidak bisa terjadi denga sendirinya. Pembakaran campuran bensin dan udara yang dikomprensikan terjadi di dalam ruang bakar (silinder blok) setelah memercikkan bunga api, sehingga diperoleh tenaga akibat pemuaian gas (eksplosif) hasil pembakaran, mendorong piston ke posisi TMB (titik mati bawah) menjadi langkah usaha. Agar busi dapat memercikkan bunga api dengan tepat, maka diperlukan suatu sistem yang bekerja secara akurat. Sistem pengapian terdiri dari berbagai komponen, yang bekerja bersama-sama dalam waktu yang sangat cepat dan singkat. Bunga api pada busi berasal dari arus listrik tegangan tinggi dimana arus ini mengalir pada waktu tertentu,jadi sewaktu arus mengalir busi memercikkan bunga api dan sewaktu tidak ada aliran, busi mati.

\section{Daya}

Daya merupakan salah satu parameter dalam menentukan performa motor. Pengertian dari daya motor adalah besarnya kerja motor tadi selama waktu tertu. Satuan yang digunakan yaitu hp (horse power). Untuk menghitung besarnya daya motor 4 langkah dapat digunakan rumus:

Dimana:

$$
P=\frac{2 \pi \cdot n \cdot T}{6000}(h p)
$$

$$
\begin{aligned}
& P=\text { Daya motor }(\mathrm{hp}) \\
& n=\text { Putaran mesin }(\mathrm{rpm}) \\
& T=\text { Torsi }(\mathrm{Nm})
\end{aligned}
$$

\section{Torsi}

Gaya tekan putar pada bagian yang berputar disebut torsi, sepeda motor digerakkan oleh torsi dari crankshaft. Torsi atau momen gaya adalah gaya untuk memutarkan suatu benda pada porosnya. Maka torsi bisa diibaratkan sebagai gaya putar terhadap suatu 
benda. Satuan yang digunakan yaitu Nm (Newton meter) atau lbs ft ('pound feet). Dari definisi ini, maka rumus Torsi adalah:

$$
T=\frac{P_{m \cdot} \cdot A \cdot L \cdot i}{a} A T A U \quad T=F x d
$$

Keterangan:

$$
\begin{array}{ll}
\mathrm{T} & =\text { Torsi }(\mathrm{N}, \mathrm{m}) \\
\mathrm{Pm} & =\text { Tekanan efektif rata-rata }\left(\mathrm{kgf} / \mathrm{cm}^{2}\right) \\
\mathrm{F} & =\text { Gaya }(\text { Newton}) \\
\mathrm{A} & =\text { Luas penampang silinder }\left(\mathrm{cm}^{2}\right) \\
\mathrm{d} & =\text { Jarak (meter) } \\
\mathrm{L} & =\text { Panjang langkah torak }(\mathrm{m}) \\
\mathrm{i} & =\text { Jumlah silinder } \\
\mathrm{a} & =\text { Jumlah siklus perputaran, } 4 \text { tak } \mathrm{a}=2 .
\end{array}
$$

\section{Konsumsi bahan bakar}

Percobaan pertama dilakukan pada motor bakar dengan bensin murni untuk mengetahui seberapa besar laju konsumsi BBM yang di butuhkan motor bakar dalam kondisi tanpa penambahan gas elektrolisa air. Untuk mengetahui fuel consumtion di gunakan persamaan sebagai berikut:

Dimana:

$$
\mathrm{FC}=\frac{V_{f} \times 3600}{t \times 1000}[L / h]
$$

$$
\begin{aligned}
& \mathrm{FC}=\text { fuel comsumtion }(\mathrm{L} / \mathrm{h}) \\
& \mathrm{V}_{\mathrm{f}}=\operatorname{volume} \text { konsumsi }(\mathrm{mL}) \\
& \mathrm{t} \quad=\text { waktu konsumsi }(\mathrm{s}) .
\end{aligned}
$$

\section{METODE PENELITIAN}

Diagram Alir Penelitian

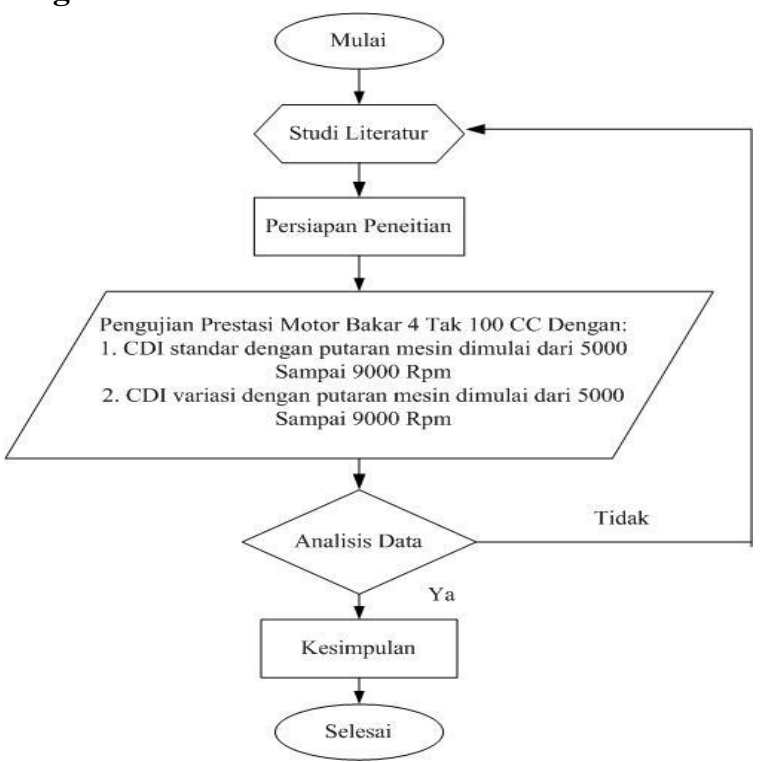

Gambar 1. Diagram Alir Penelitian
Metode penelitian yang digunakan dalam penelitian ini adalah metode eksperimental. Metode eksperimental adalah metode yang digunakan untuk menguji pengaruh dari suatu perlakuan atau desain baru dengan cara membandingkan desain tersebut dengan desain tanpa perlakuan sebagai kontrol atau pembanding. Metode eksperimental dapat juga berarti membandingkan pengujian beberapa variasi perlakuan dengan pengujian tanpa variasi sebagai pembanding.

\section{Alat dan Bahan}

Alat yang digunakan dalam pengujian ini Dynamometer. Dynamometer dapat dilihat pada gambar 2. di bawah ini.

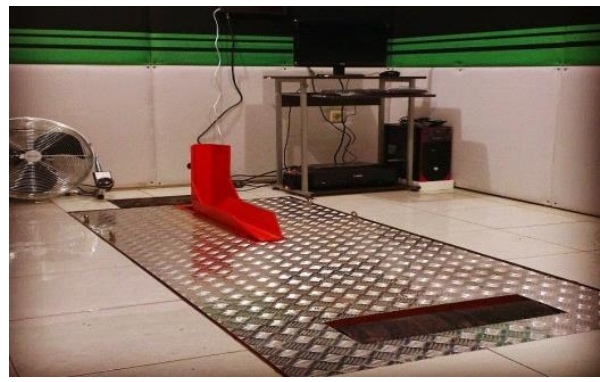

Gambar 2. Dynamometer

Bahan yang digunakan dalam pengujian adalah sebagai berikut:

1. Motor bensin 4 langkah dengan spesifikasi sebagai berikut

$\begin{array}{ll}\text { Jenis } & : \text { Motor } 4 \text { tak } \\ \text { Tipe mesin } & : 4 \text { langkah, (OHC) } \\ \text { Diameter x langkah } & : 50 \times 49,5 \mathrm{~mm} \\ \text { Volume langkah } & : 100 \mathrm{cc} \\ \text { Perbandingan kompresi } & : 1: 8,8 \\ \text { Maximum power } & : 10,8 \mathrm{HP} / 8.000 \mathrm{rpm} \\ \text { Kapasitas Oli mesin } & : 0,9 \text { liter } \\ \text { Gigi transmisi } & : 4 \text { percepatan } \\ \text { Starter } & : \text { Pedal dan Elektrik } \\ \text { Sistem pengapian } & : \text { AC-CDI } \\ \text { Tahun Pembuatan } & : \text { : } 984-2005 \\ \text { Negara Pembuat } & : \text { Jepang }\end{array}$

2. CDI variasi Dengan Spesifikasi Sebagai Berikut:

$\begin{array}{ll}\text { Merk } & \text { : BRT (Bintang Racing Team) } \\ \text { Type } & : \text { DIGITAL AC sistem } \\ \text { Operating Voltage } & :- \\ \text { Mikroprosessor } & : \text { NXP founded by philips semicondutor } \\ \text { Current Consumption } & :- \\ \text { Output Max } & : 300 \text { volt } \\ \text { Operation Temp } & :-15 \text { to } 80 \\ \text { Putaran Mesin } & : 400 \text { to } 20.000 \mathrm{Rpm}\end{array}$

3. CDI Standar Dengan Spesifikasi Sebagai Berikut:

\section{Metode Penelitian}




$\begin{array}{ll}\text { Merk } & : \text { Shindengen } \\ \text { Tipe } & : \text { AC sistem } \\ \text { Output Max } & : 200 \text { volt } \\ \text { Fitur } & : \text { Advance Ignition Timin } \\ \text { Putaran Mesin } & : 300 \text { to } 20.000 \text { Rpm } \\ \text { Aplikasi } & : \text { Standar Pabrikan }\end{array}$

\section{Analisis}

Model analisis data yang akan dipakai yaitu analisis perbandingan (komparasi) hasil antara kelompok eksperimen (kelompok yang dikenai treatment) dengan kelompok pembanding atau kelompok kontrol (yang dikenai treatmen berbeda atau treatmen yang biasa). Dalam hal ini penulis akan membandingkan hasil pengujian performa dan konsumsi bahan bakar dari rpm rendah sampai rpm tinggi dari CDI standart dan CDI variasi pada motor 4 tak $100 \mathrm{cc}$.

\section{HASIL DAN PEMBAHASAN}

\section{Konsep Pengujian}

Pengujian yang dilakukan dalam penelitian ini adalah menguji prestasi mesin suatu motor bakar pembakaran dalam. Untuk menguji prestasi mesin suatu motor bakar dilakukan dengan dynamometer atau yang juga disebut sebagai dynotest. Dynotest merupakan mesin (roller) yang di tananmkan pada lantai sehingga kendaraan dapat digerakkan atau dijalankan di atas roller tersebut. Dengan berjalannya kendaraan diatas roller dapat diukur daya,torsi dan konsumsi bahan bakar pada suatu mesin.

Tabel 1. Data Hasil Pengujian Hubungan Daya Terhadap Putaran Mesin

\begin{tabular}{|c|c|c|c|c|c|c|}
\hline \multirow{3}{*}{$\begin{array}{c}\text { Putaran } \\
\text { mesin } \\
\text { (RPM) }\end{array}$} & \multicolumn{6}{|c|}{ Daya (HP) } \\
\hline & \multicolumn{3}{|c|}{$\begin{array}{c}\text { Pengujian } \\
\text { CDI Standart }\end{array}$} & \multicolumn{3}{|c|}{$\begin{array}{c}\text { Pengujian } \\
\text { CDI Variasi } \\
\text { BRT POWERMAX }\end{array}$} \\
\hline & $\mathrm{Ke}-1$ & $\mathrm{Ke}-2$ & $\mathrm{Ke}-3$ & $\mathrm{Ke}-1$ & $\mathrm{Ke}-2$ & $\mathrm{Ke}-3$ \\
\hline 5000 & 5.3 & 5.5 & 5.6 & 5.7 & 5.8 & 5.7 \\
\hline 6000 & 5.8 & 6.1 & 6.2 & 6.4 & 6.5 & 6.5 \\
\hline 7000 & 5.8 & 6.2 & 6.1 & 6.6 & $\begin{array}{ll}6.8 \\
\end{array}$ & 6.9 \\
\hline 8000 & 5.5 & \begin{tabular}{|l|}
5.8 \\
\end{tabular} & 5.6 & 6.4 & $\begin{array}{l}6.3 \\
\end{array}$ & 6.6 \\
\hline 9000 & 4.5 & 4.7 & 4.8 & 5.6 & 5.5 & 5.6 \\
\hline $\begin{array}{l}\text { RATA - } \\
\text { RATA }\end{array}$ & & 5,0 & & & 6,2 & \\
\hline
\end{tabular}

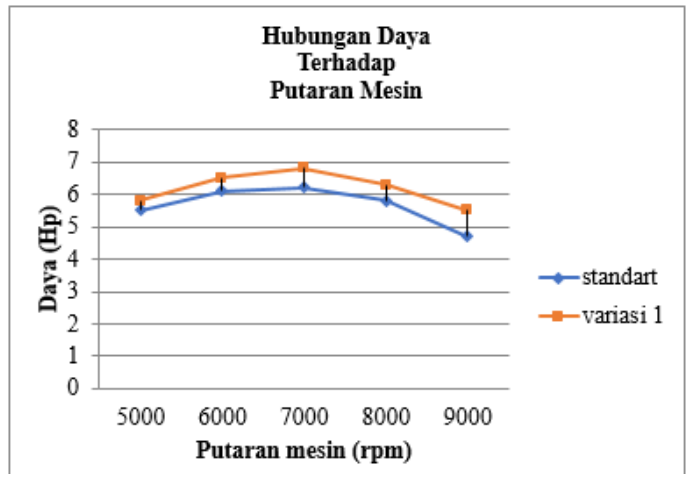

Gambar 3. Grafik Hubungan Daya Terhadap Putaran Mesin

Pada gambar grafik daya diatas menunjukkan bahwa tertinggi CDI standar pada putaran mesin 7000 rpm dengan daya 6,2 HP dan terendah pada putaran mesin $9000 \mathrm{rpm}$ dengan daya 4,5 Hp. Pada CDI varisi daya tertingginya dengan nilai $6,9 \mathrm{Hp}$ pada putaran mesin $7000 \mathrm{rpm}$ dan daya terendah 5,5 $\mathrm{Hp}$ pada putaran mesin $9000 \mathrm{rpm}$.

Dari uraian di atas, hubungan daya terhadap putaran mesin menggunakan CDI standar dan CDI variasi, didapat daya optimum. Daya optimum pada CDI standar terdapat pada putaran mesin $7000 \mathrm{rpm}$, pada CDI variasi $7000 \mathrm{rpm}$. Peningkatan daya disebabkan karena saluran masuk dan buang tepat sehingga tenaga yang dihasilkan untuk performa motor yang belum memperbesar piston dan memperpanjang langkah telah cukup pada ruang bakar.

Tabel 2. Data Hasil Pengujian Hubungan Torsi Terhadap Putaran Mesin

\begin{tabular}{|c|c|c|c|c|c|c|}
\hline \multirow{3}{*}{$\begin{array}{l}\text { Putaran } \\
\text { mesin } \\
\text { (RPM) }\end{array}$} & \multicolumn{6}{|c|}{ Torsi (N.m) } \\
\hline & \multicolumn{3}{|c|}{$\begin{array}{l}\text { Pengujian } \\
\text { CDI Standar }\end{array}$} & \multicolumn{3}{|c|}{$\begin{array}{c}\text { Pengujian } \\
\text { CDI Variasi } \\
\text { BRT powermax hyperban }\end{array}$} \\
\hline & Ke-1 & $\mathrm{Ke}-2$ & $\mathrm{Ke}-3$ & Ke-1 & $\mathrm{Ke}-2$ & $\mathrm{Ke}-3$ \\
\hline 5000 & 7.49 & 7.64 & 7.81 & 7.91 & 8.12 & 8.08 \\
\hline 6000 & 6.82 & 7.15 & 7.27 & 7.47 & 7.59 & 7.65 \\
\hline 7000 & 5.76 & 6.20 & 6.13 & 6.59 & 6.79 & 6.87 \\
\hline 8000 & 4.88 & 5.10 & 4.88 & 5.62 & 5.55 & 5.81 \\
\hline 9000 & 3.55 & 3.69 & 3.72 & 4.40 & 4.26 & 4.34 \\
\hline RATA & \multicolumn{3}{|c|}{5,87} & \multicolumn{3}{|c|}{6,47} \\
\hline
\end{tabular}




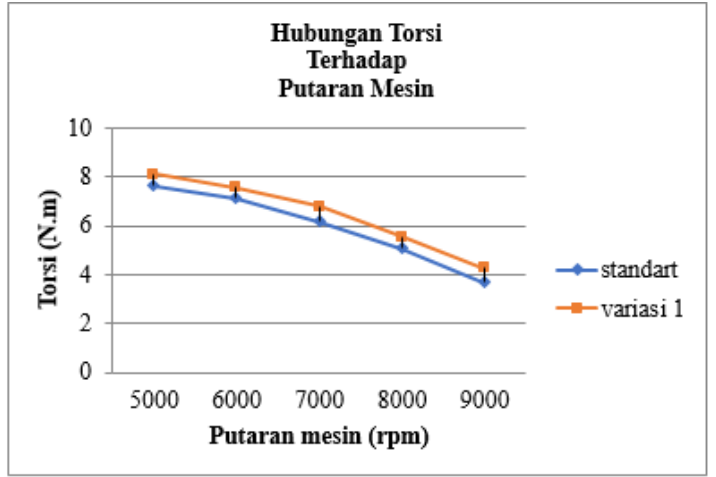

Gambar 4. Grafik Hubungan Torsi Terhadap Putaran Mesin

Dari data torsi terhadap putaran mesin pada penggunaan CDI standart dan CDI variasi diperoleh nilai torsi tertinggi dan terendah. Untuk nilai tertinggi terdapat pada CDI standar sebesar ( 7,81 N.m) pada putaran mesin $5000 \mathrm{rpm}$, dan nilai terendahnya ( 3,55 N.m) pada putaran 9000 rpm. Selanjutnya torsi dengan CDI variasi dengan nilai tertinggi ( 8,12 N.m) pada putaran $5000 \mathrm{rpm}$, dan nilai terendah pada putaran 9000 rpm sebesar (4,26 N.m.

Dari uraian di atas torsi naik pada putaran rendah dan turun pada putaran tinggi, hal tersebut disebabkan oleh pembesaran dinding pada saluran silinder dan langkah piston tetap (standar). Untuk torsi yang turun pada putaran menengah sampai tinggi disebabkan oleh torsi berbanding lurus dengan tenaga, terutama pada putaran bawah mesin. Tapi seriring naiknya putaran mesin, tenaga juga naik sementara torsi turun.

Tabel 3. Data Hasil Pengujian FC CDI Standar Terhadap Putaran Mesin

\begin{tabular}{|c|c|c|c|c|c|c|}
\hline \multicolumn{7}{|c|}{ FC } \\
\hline Rpm & $\begin{array}{c}\text { V } \\
(\mathrm{ml})\end{array}$ & $\begin{array}{c}\text { tl } \\
(\mathrm{s})\end{array}$ & $\begin{array}{c}\text { 2 } \\
(\mathrm{s})\end{array}$ & $\begin{array}{c}\text { t3 } \\
(\mathrm{s})\end{array}$ & $\begin{array}{c}\text { T rata- } \\
\text { rata } \\
(\mathrm{s})\end{array}$ & $\begin{array}{c}\text { FC } \\
(\mathrm{L} / \mathrm{h})\end{array}$ \\
\hline 4000 & 30 & 155,1 & 133,5 & 141,9 & 143,5 & 0,75 \\
\hline 5000 & 30 & 146,3 & 117,2 & 132,5 & 132 & 0,81 \\
\hline 6000 & 30 & 137,6 & 102,7 & 117,2 & 119,1667 & 0,90 \\
\hline 7000 & 30 & 130,1 & 101,4 & 114,6 & 115,3667 & 0,93 \\
& & & & & & \\
\hline
\end{tabular}

Tabel 4. Data Hasil Pengujian FC CDI Variasi Terhadap Putaran Mesin

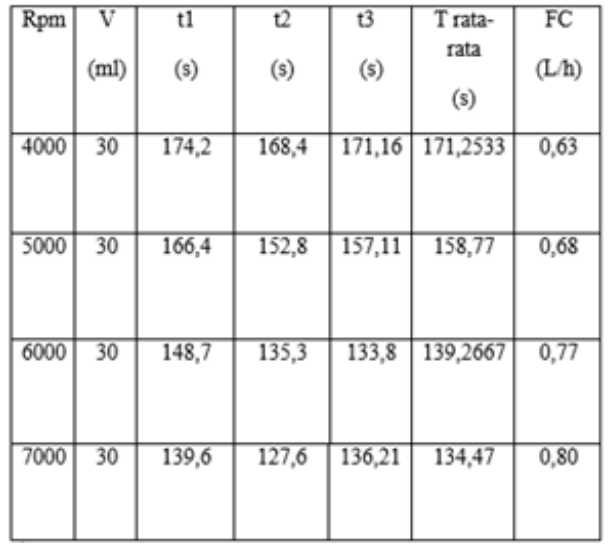

Di bawah ini Grafik Hasil Pengujian FC CDI Standar dan CDI Variasi Terhadap Putaran Mesin

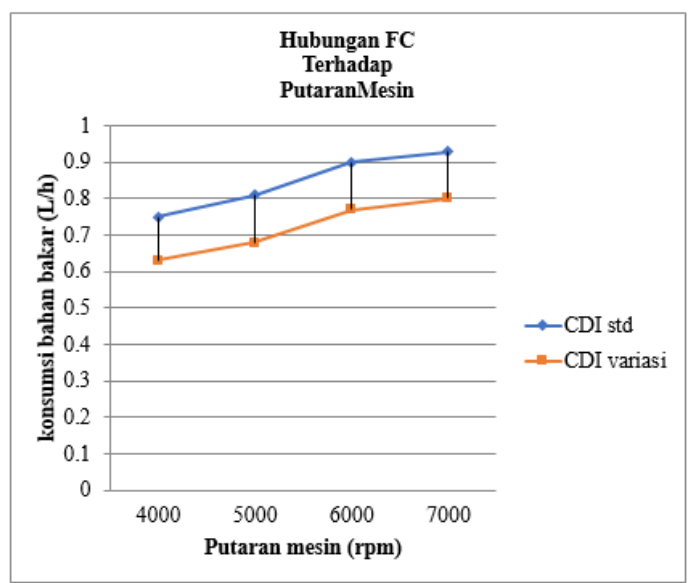

Gambar 5. Grafik Hasil Pengujian FC CDI Standar dan CDI Variasi Terhadap Putaran Mesin Tabel 5. Data Rata-Rata Performa Motor

\begin{tabular}{|c|c|c|c|}
\hline \multicolumn{4}{|c|}{ Rata-Rata Performa Motor } \\
\hline & $\begin{array}{c}\text { Torsi } \\
\text { (N.m) }\end{array}$ & $\begin{array}{c}\text { Daya } \\
(\mathrm{Hp})\end{array}$ & FC (L/h) \\
\hline CDI Standar & 5,87 & 5,0 & 0,8475 \\
\hline CDI variasi & 6,47 & 6,2 & 0,72 \\
\hline
\end{tabular}

\section{PENUTUP}

\section{Kesimpulan}

Dari data hasil pembahasan performa motor 4 tak 100 cc yang diuji, telah mendapat nilai rata-rata dari daya, torsi, dan konsumsi bahan bakar spesifik yang berbeda. Yaitu menggunakan CDI standart dengan nilai daya $(5.0 \mathrm{Hp})$ sedangkan untuk torsi $(5.87 \mathrm{Hp})$ dan konsumsi bahan bakar specific $(0,8475 \mathrm{~L} / \mathrm{h})$.

Nilai yang diperoleh dari data hasil rata-rata menggunakan CDI (BRT POWER MAX) dengan 
daya $(6,2 \mathrm{Hp})$, sedangkan nilai torsi $(6,47 \mathrm{Hp})$ dan untuk bahan bakar spesifik $(0,72 \mathrm{~L} / \mathrm{h})$. Dapat disimpulkan bahwa menggunakan CDI (BRT POWER MAX) mempunyai nilai yang lebih unggul dan mampu menambah performa serta memper irit kendaraan dibanding menggunakan CDI standart.

\section{Saran}

Berdasarkan hasil penelitian yang telah disimpulkan di atas, maka penulis merekomendasikan berupa saran-saran sebagai berikut:

1. Diperlukan penelitian lebih lanjut tentang perbandingan atau analisis tentang CDI yang berbeda untuk mendapat hasil performa motor yang maksimal.

2. Kendaraan harus di servis terlebih dahulu, pentingnya bahan uji yang berbeda- beda untuk mendapat hasil yang maksimal.

3. Pengambilan data sebaiknya diberi jeda waktu istirahat untuk kendaraan uji agar kondisi mesin dalam keadaan optimal dan data yang di hasilkan valid.

4. Bagi mahasiswa universitas muhammadiyah jember terutama jurusan teknik mesin disarankan untuk lebih kreatif dan inovatif dalam memimilih peralatan dan bagi universitas muhammadiyah jember perlengkapan perlu di lengkapi, seperti halnya alat dynotes.

\section{DAFTAR PUSTAKA}

Arismunandar, wiranto. 1980. Penggerak mula motor bakar torak.bamdung.

Fadoli, mustaqim, zulhan. 2011. Analisa perbandingan daya dan komsumsi bahan bakar antara pengapian standart dengan pengapian menggunakan booster mesin Toyota kijang seri $7 \mathrm{k}$. universitas panca sakti tegal.

Fitri, wjayanti dan Dadan Irwan. 2014 hal: 34 dalam M. Taufik 2016. Pengaruh Diameter Intake Valve Terhadap Unjuk Kerja Mesin Bensin Empat Langkah. Malang: Universitas Brawijaya.

Hidayat, 2012. Prinsip kerja dari motor bensin.

Haryono, 1997. Bunga api pada busi berasal arus listrik tegangan tinggi dimana arus ini mengalir pada waktu tertentu.

Jama, Jalius dan Wagino. 2008. Teknik Sepeda Motor Jilid 1. Jakarta: Direktorat Pembinaan Sekolah Menengah Kejuruan, Direktorat Jenderal
Manajemen Pendidikan Dasar dan Menengah, Departemen Pendidikan Nasional.

Pieter W.Tetelepta, 2014 analisis modifikasi volume silinder terhadap torsi, daya, dan komsumsi bahan bakar kendaraan bermotor roda dua universitas patimura.

Pulkrabek, 2004, Fergueson, 1986 Heywood 1988. Dalam FX sukidjo 2011 performa mesin motor 4 langkah berbahan bakar premium dan pertamax. 